Vol 41 (2016) No 184 213-233

\title{
Predictors of Organizational Socialization of Instructors in Higher Education
}

Fatma Ataman ${ }^{1}$, Yaşar Kondakçı ${ }^{2}$

\begin{abstract}
This study aims to investigate the relationship between organizational socialization and various organizational (type of university, training, work conditions, knowledge sharing) and individual (academic degree, teaching experience, length of employment at current work place, job satisfaction, commitment, self-efficacy) level factors, both factors taken together focusing on the content, context and process dimensions of socialization. For this aim, data from 737 public and private university English language instructors were collected with an inventory consisting of three parts made up of self-developed and pre-developed scales. Taking each dimension of organizational socialization as a criterion variable, three sets of predictors were defined for three separate hierarchical regression analyses. The results revealed that socialization of instructors to the organization, department, and task are significantly predicted by several organizational and individual variables. Knowledge sharing and training are the strongest organizational level predictors while job satisfaction, selfefficacy for instructional strategies, and affective commitment are the strongest individual level predictors. The results suggest higher education administrators adapt organizational and individual level managerial strategies to facilitate organizational, department and task socialization in higher education organizations.
\end{abstract}

Keywords

Organizational socialization
Faculty induction
Higher education
Organizational commitment
Self-efficacy
Article Info
Received: 16.12 .2015
Accepted: 11.04 .2016
Online Published: 27.04 .2016

\section{Introduction}

Organizational socialization process transforms the newcomers from total outsider to effective and participating members of the organization by adopting new social and professional skills, attitudes, dominant cultural elements and behavioral patterns (Chao, O'Leary-Kelly, Wolf, Klein, \& Gardner, 1994; Louis, 1980; Thomas \& Anderson, 1998). One of the first definitions of organizational socialization was provided by Van Maanen and Schein (1977). They defined the concept as a process of acquiring norms, beliefs, values, attitudes and languages features of the organizations. As a result of socialization, the new comers accomplish fit and fulfill the expectations like their peers in the organization. In a similar definition, Jablin (1982, p. 276) highlighted the enculturation aspect of socialization and defined the concept as "the process by which organizational members become a part of, or absorbed into, the culture of an organization." Likewise, Schein (1968) highlighted the reshaping effect of socialization to accomplish fit in the organization. Although early definitions of socialization position the newcomer as

${ }^{1}$ Turkish Education Association, Turkey, fatma.ataman@ted.org.tr

${ }^{2}$ Middle East Technical University, Faculty of Education, Department of Educational Sciences, Turkey, kyasar@metu.edu.tr 
a passive recipient of organizational features, more recent definitions of socialization highlighted the give-and-take or reciprocal nature of socialization in which both the newcomer and organization contribute to each other (Tierney, 1997). All of these definitions highlight importance of the alignment between the newcomers' interest, concerns, and values with those of the organization (Trowler \& Knight, 1999). In that sense, it is a dynamic and interactive process between the organization and the new comer.

Organizational socialization and induction practices in higher education are significant and are to be investigated as a separate entity as higher education institutions are different from business organizations. Birnbaum (1988) proposed that higher education institutions are managed much differently from most organizations, and thus, they have a distinctive culture. One cause for difference is the multiple missions of teaching, research and service (Birnbaum, 1988). Furthermore, as instructors gain experience during their socialization process, they experience a continuous change as a member of the faculty and as a teacher. Despite its unique role in faculty retention, faculty socialization has not been adequately investigated in a higher education context. In fact, a successful socialization process on the part of the instructors positively contributes to their productive behaviors including organizational commitment and job satisfaction, which in turn, positively contributes to their teaching and research. However, reducing turnover rate and retaining teachers is difficult if their socialization process is not successful (Wharton, Potter, \& Parry, 2004). Previous literature documents evidence on the negative impact of failing socialization process on the quality of professional life (Johnsrud \& Heck, 1998) and job satisfaction (Boyer, Altbach, \& Whitelaw, 1994). Hence, higher education organizations face an increasing pressure in attracting and retaining quality faculty. Organizational socialization serves several functions in this respect. It enhances organizational commitment, teaches members the culture, rules and procedures of the institution (Wharton et al., 2004).

Another point which gives significance to this study is the absence of a theoretical framework in higher education for understanding academics' and instructors' socialization process. However, this gap is evident for the broader organization science field as well largely because of the complexity of the concept of socialization (Saks \& Ashforth, 1997). Nevertheless, various concepts in psychology and organization sciences theoretical perspectives form the basis for studies in the field. Van Maanen and Schein (1977) provided the first socialization model. In their model they proposed six bipolar socialization tactics, which explained how methods of socialization influence adaptation of the new comers to the work setting. Defined as,

"group (a group of recruits and putting them through a common set of experiences together...) versus individual (apprenticeships, internships...), formal (a newcomer is more or less segregated from regular organizational members while being put through a set of experiences tailored explicitly for the newcomer...) versus informal (socialization processes do not distinguish the newcomer's role specifically, new recruits learn through trial-and-error...), sequential (the degree the occupation specifies a given sequence of steps leading to the target role...) versus random (the steps in socialization are ambiguous or changing...), serial (experienced members groom newcomers to assume similar kinds of positions...) versus disjunctive (there are no role models and newcomers are not following in the footsteps of others...), investiture (ratify and document the viability and usefulness of those personal characteristics the recruits bring into the organization...) versus divestiture (try to deny and strip away certain personal characteristics...), fixed (socialization processes give many clues as to when to expect a given boundary passage...) versus variable (socialization processes give few clues as to when to expect a given boundary passage...), these tactics shape the role orientation of newcomers and their adjustment to the organization" (Van Maanen \& Schein, 1977, pp. 37-68). 
Bandura's (1986) social cognitive theory contributes to our understanding of the theoretical bases of the socialization process. Social cognitive theory asserts that behavior, cognition and other personal dispositions interact with the environment in a reciprocal manner, which determine each individual's psychosocial state (Bandura \& Wood, 1989). Bandura and Wood defined vicarious learning and mastery modeling, goal systems and self-regulatory mechanisms as three cognitive dimensions shaping individual behaviors in organizational setting (Bandura \& Wood, 1989). Self-efficacy theory, which is viewed as an important component of the self-regulatory mechanism, identifies four sources of information influencing one's beliefs about their capacity to accomplish a task and regulating the level of motivation to undertake a task. Four sources of information are enactive mastery experience (positive impact of previous success and accomplishments on self-efficacy believes), vicarious experience (building self-efficacy by observing others', typically peers, success and accomplishment), verbal persuasion (convincing people that they have the capacity to succeed), and physiological and affective states (being able to control physiological symptoms such as pounding hearth, sweating palms, trembles while performing a challenging task) (Bandura, 1986, 1997).

Being a complex and continuous process, organizational socialization of a newcomer can be studied by referring to various theoretical perspectives complementing each other, and thus, through a heterogeneous theoretical perspective to focus on the content, context and process dimensions of socialization. As the related literature indicated, several studies have been conducted to reveal the functioning of socialization process and the factors associated with this process. While these studies have brought in-richness to the field, they have also led to various approaches to understand and analyze the socialization process. As stated above, due to a large variety of approaches to define socialization process, there has been a disagreement among the scholarship regarding the dimensions of socialization (e.g., Jablin, 1982; Louis, 1980; Thomas \& Anderson, 1998; Tierney, 1997; Van Maanen \& Schein, 1977). If the dimensions were firmly identified, developing a certain instrument to define and measure socialization would be easy. However, neither the dynamic and complex nature of socialization process nor the richness of approaches in the field would allow it, as a result of which there has been little empirical research which defines and evaluates the dimensions of socialization process. Within the scope of this study, socialization literature was reviewed to elaborate on the type of organizational and individual level factors which can be identified as predictors of socialization. While identifying these factors, content, process and environment dimensions of socialization were taken into consideration so that the results of the study could be holistic. The following section elaborates on the role different factors which have predictive value for organizational socialization of faculty members.

\section{Predictors of Faculty Socialization}

Capturing a true understanding of organizational socialization necessitates counting on the predictive value of various individual and organizational level variables. The literature on organizational socialization provides theoretical guidelines for building relationship between different dimensions of organizational socialization, on the one hand, and commitment, self-efficacy, knowledge sharing, job satisfaction, and training and mentoring, on the other.

\section{Organizational Commitment}

Conceptual and empirical evidence suggest organizational commitment as a potential correlate of organizational socialization. Organizational commitment refers to the bound that individuals develop to the organizations they work for (Ketchand \& Strawser, 2001) or to the bond of the employee to the organization (Mathieu \& Zajac, 1990). Although initial literature conceptualizes commitment as a unidimensional construct (e.g., Hrebiniak \& Alutto, 1972), recent literature conceptualizes the construct as a multidimensional one. For example, O'Reilly and Chatman (1986) defined commitment as the attachment of the employee to the organization and suggested identification, internalization and compliance as three dimensions of concept. This definition and understanding of commitment provides a valuable perspective for counting on commitment as a predictor of organizational socialization. However, Allen and Meyer's (1990) multidimensional framework of commitment provides a valuable perspective on the predictive value of commitment for organizational socialization. The authors 
proposed affective (the desire work at a particular organization), continuance (the need to work at a particular organization), and normative (the obligation to work at a particular organization). Affective commitment refers to the employee's emotional attachment to the organization, which fosters the employees' identification with the organization. Affective commitment typically strengthen individual's internal desire to stay at the organization. As a continuous commitment the employee makes a cost benefit calculation in relation to rights and benefits they have at the current organization and what they lose when they leave the organization. Employees whose continuous commitment is strong typically stay at the organization because there is cost associated with leaving the organization. In normative commitment employees stay with the organization because they feel that they are obliged to stay at the current organization (Allen \& Meyer, 1990). In all three types of commitment the individual is involved in a subjective judgment about whether to stay or leave the organization.

Although there are few studies theorizing the direct relationship between commitment and socialization, several studies provided anecdotal evidence for the relationship between these two constructs. For example, in their study about the consequences of organizational commitment, Mathieu and Zajac (1990) reported the predictive value of organizational commitment for performance and absenteeism. In other words, commitment is likely to contribute to task socialization of the employees. Besides, previous literature suggest direct causality between intensive socialization programs and commitment to values of the organization (Caldwell, Chatman, \& O'Reilly, 1990). Quite a few studies have also been carried out in Turkey investigating the relationship between organizational commitment and various socialization practices both in the field of psychology (e.g., Ok, 2007; Ünüvar, 2006) and education (e.g., Gür, 2008).

\section{Self-efficacy}

The construct of self-efficacy is a central concepts in Bandura's social cognitive theory. The concept initially was defined as "beliefs in one's capabilities to organize and execute the courses of action required to produce given attainments" (Bandura, 1997, p. 3). Self-efficacy is related to individual's cognitive judgment about their capacity to fulfill a task. Hence, it influences the type and magnitude of the goals they specify and their decision choices in their professional and private lives. Individuals set goals and motivate themselves to attain their goals. During this process, they evaluate their performance in order to make a judgment about their capabilities. Those who have a high sense of self-efficacy resist longer when faced with challenges compared to those who have a lower sense of selfefficacy (Gür, 2008). Although the literature does not provide evidence on the direct relationship between efficacy and socialization, different studies provided indirect evidence for such relationship. Coladarci (1992) found that teachers with a high sense of self-efficacy are highly committed to their profession. Glickman and Tamashiro (1982) found that teachers with a low sense of self-efficacy tend to leave the teaching profession. In a study by Jones (1986) about socialization tactics, self-efficacy, and newcomers' adjustment to organizations, it was concluded that self-efficacy regulates the learning process of a newcomer and that socialization tactics produce a stronger protective role orientation when newcomers possess a low level of self-efficacy. A limited number of studies on the relations between self-efficacy and socialization show-that self-efficacy fosters socialization of the new comers.

\section{Knowledge Sharing}

Knowledge sharing refers to a process by which information and knowledge is exchanged and based on the exchanged information and new knowledge is created by the receiver (Leistner, 2010). The continuous flow of knowledge among various organizational units increases the performance and intellectuality of employees. Knowledge sharing has been recognized as an important contribution to the competitive advantage of the organization (Widen-Wulff, 2007). Research shows that knowledge sharing leads to increased performance and competitiveness in organizations. Knowledge sharing is particularly important for the newcomers because they seek information to reduce uncertainty (Ashford \& Cummings, 1985), and also when there is a gap between the amount of knowledge they have and the amount of knowledge they need to perform their job. Knowledge sharing can help newcomers adjust to their job and the new environment; in other words, socialization of newcomers becomes effective as 
they have access to knowledge. Knowledge sharing has been taken into consideration in recent years as proactive socialization has gained importance because employees with proactive socialization tendencies have an active orientation towards decreasing the uncertainty they are faced with (Miller \& Jablin, 1991). Another study reported that knowledge of various contextual domains, higher satisfaction and commitment of newcomers are related to knowledge sharing (Ostroff \& Kozlowski, 1992). Saks and Ashforth (1997) in their study on the relation between socialization tactics and knowledge sharing suggested that socialization tactics that are being used set the base for knowledge sharing. Although these studies provide mixed evidence on the direction of the relationship between socialization and knowledge sharing, they are still inspiring to assume a predictive role of knowledge sharing for socialization.

\section{Job Satisfaction}

According to Spector (1997, p. 2), "job satisfaction is simply how people feel about their jobs and different aspects of their jobs." According to Locke (1976), job satisfaction is a positive affective state which is based on one's fulfilling job experience. In other words, job satisfaction indicates the fulfillment of one's needs. As a result, job satisfaction is not independent of workplace conditions offered to the individual including the work setting, role definition, and outcomes of the work they perform (Wanous \& Lawler, 1972). In that sense, job satisfaction is closely related to a successfully socialization process (Bauer, Bodner, Erdogan, Truxillo, \& Tucker, 2007). Newcomers learn key features of the organization and their work through socialization (Van Maanen \& Schein, 1977). As in the case of knowledge sharing, the literature on job satisfaction does not suggest a definite direction on the relationship between job satisfaction and socialization. However, based on the literature it can be argued that satisfactory job experiences breed socialization and vice versa.

\section{Newcomer Training and Mentoring}

In this study, pre-service training refers to the training provided to the new comers at the beginning of work experience in a new work setting while in-service training refers to the training provided during their work experience. When newcomers start working in an organization, they need to learn various skills so as to perform in the new job environment. This is enabled through certain means such as training sessions, orientations, introductory courses, which are expected to increase newcomers' success in the organization. It is believed that both pre-service and in-service training provided to the employees are beneficial for their adjustment in the new workplace since the process of socialization is a stressful period of transition due to uncertainty about newcomers' ability to cope with the demands of the organization and the ambiguity related to newcomers' role in the organization. Saks (1996) found that pre-service training help newcomers reduce their uncertainty. Similarly Feldman (1989) stated training programs as the main tools of socializing the newcomers, adding that formal training programs have an important role in how individuals recognize their new job environment and adjust to it; and therefore, training programs have become synonymous with socialization. Nelson and Quick (1991) found formal training to be the most available practice of organizational socialization. Saks (1996) elaborated on Nelson and Quick's study and considered the amount of training as well and found that the ratings of newcomers' about how helpful the training increased as the amount of training increased. Saks (1996) also found that work outcomes were related to the amount and helpfulness of the training.

Mentorship has also been recognized as an important correlate of the socialization process. Newcomers often report that they have learned a great deal from a mentor, who is an older and more experienced employee advising, counseling and enhancing their development (Greenberg \& Baron, 1993). Mentorship is an effective practice of transmitting knowledge on organizational features, issues and practices to the new comers (Ostroff \& Kozlowski, 1993). More importantly, the mentors are key agents in helping the new comers to assimilate organizational values and accomplishing a fit in the organization (Chatman, 1991). Louis (1990) stated that interaction with members in the organization significantly contributes to sense making and situation identification, as well as adopting the culture. According to Louis, Posner, and Powell (1983), such an interaction can occur during mentor programs 
when newcomers establish rapport and relation with experienced members in the organization. Angelides and Mylordou (2011) claimed that mentorship is a widespread way to allow employees meet challenges of socialization during early years of work experience in a new organizational setting. Mentorship guides new comers on how to develop relationships with peers at work, join social setting, set the knowledge base of their professional practice, develop professional skills for the conduct of the job, and get cultural elements of the work setting (Roehrig, Bohn, Turner, \& Pressley, 2008).

The literature regarding organizational socialization which is briefly covered in this section suggests that there is an empirical gap on the predictive value of individual and organizational level factors for organizational socialization. Considering this gap in the literature, this study aimed to answer the following research question: what is the predictive value of organizational (type of university, training, work conditions, knowledge sharing) and individual (academic degree, teaching experience, length of employment at current work place, job satisfaction, commitment, self-efficacy) level factors for organization, department and task socialization?

\section{Method}

\section{Sampling}

According to 2015 data there are 10239 English language instructors in Turkey (YÖK, 2015). Of this population, 6337 are women and 3902 are men while 7338 are working at public universities and 2871 are working at foundation universities. Considering the size of population, random sampling did not seem feasible. Thus, cluster sampling selection method was used in this study to collect data from instructors employed in the preparatory schools of universities. For this purpose, using cluster sampling as the method for selection, four cities in Turkey (Ankara, İstanbul, Eskişehir, and Konya), and one city in Northern Cyprus Turkish Republic were chosen. Considering accessibility and willingness to participate in the study, 10 universities in Ankara, two universities in İstanbul, two universities in Eskişehir, one university in Konya, and one university in Northern Cyprus Turkish Republic constituted the accessible population of the study. In order to address the research question of the study, data were collected from 737 English language instructors working at 16 public and private universities selected from four cities in Turkey and Turkish Republic of Northern Cyprus via cluster sampling. In the main study, of the participants, 598 (81.1\%) were employed at public universities while $139(18.9 \%)$ were employed in private universities. The majority of participant instructors were female $(81.3 \%)$. Average age of participant instructors was 34.06 years $(\mathrm{SD}=8.47)$, ranging between 21 and 66 . Of the participants, $49 \%$ had B.A. degree, $45.2 \%$ had M.A. degree, and $5.8 \%$ had Ph.D. degree. Concerning pre- and in-service training, $54.3 \%$ of the participants reported to have had pre-service training, $71.8 \%$ of them reported to have had in-service training, and $28.7 \%$ of the reported to have had mentor support. Average teaching experience of participants was 10.9 years $(\mathrm{SD}=8.17)$, ranging between 6 months and 43 years; average work experience at the current institution was 8.2 years $(\mathrm{SD}=7.35)$ ranging between 6 months and 38 years. When the instructors were asked about their work experience at the university where they are currently employed, the results showed that $34.2 \%$ of the participants have been working in their current institution for $1 / 2$ to 3 years, and $23.5 \%$ of the participants have been employed in their current institution for 4 to 7 years, while only $4.2 \%$ of the participants have been employed in their current institution for 24 or more years. The average work experience of the participants at the university where they are currently employed is 8.16 years, changing with standard deviation of 7.35.

\section{Measures}

Both in the pilot study and the main study, an inventory consisting of several different scales and questions was utilized for collecting data. The inventory was made up of three parts. In part 1 , demographic information and part 2 included questions about job experience (e.g., training, mentoring support, employee benefits). Part 3 consisted of one adapted scale (Newcomer Socialization Scale), and four pre-developed scales (Knowledge Sharing Scale, Job Satisfaction Scale, Organizational Commitment Scale and Teachers' Sense of Efficacy Scale) to collect data for the criterion and predictors: 


\section{Knowledge Sharing Scale}

Relying on a large scale and mixed method study faculty socialization in Turkey, the knowledge sharing scale was developed by Haser and Kondakçı (2011). The scale is a one dimensional scale and includes 5 items on employee's (in our case the instructors') access to necessary knowledge for the performance of his/her job. The items ask the participant to rate each item on a 5-point-likert scale ranging from strongly disagree (1) to strongly agree (5). In the original study, the internal consistency reliability test (Cronbach's Alpha) yielded the value of .83 while in the current study the same test yielded the value of 89 .

\section{Job Satisfaction Scale}

The original form of this scale was developed by Hulpia and Devos (2010), and they stated that their Job Satisfaction Scale (JSS) is based on Job Enthusiasm Scale of Dewitte and De Cuyper (2003). JSS is one dimensional scale and includes six items about positive feelings of participants with their current job, indicating to what extent instructors are satisfied with their job. The scale was adapted into Turkish by Haser and Kondakçı (2011). In the original study the Cronbach's Alpha yielded the value of .86. In this study the same test yielded the value of .90 .

\section{Newcomer Socialization Questionnaire}

Turkish adaptation of Newcomer Socialization Questionnaire (NSQ) developed by Haueter, Macan, and Winter (2003) was used to measure organizational socialization in this study. The original version of the NSQ has three dimensions: organization socialization, department socialization and task socialization. There are 12 items for both organization and department socialization, and 11 items for task socialization.

Within the scope of this study, NSQ was adapted to Turkish by the researchers in this study. After Haueter and her colleagues' permission was obtained for adaptation of the scale, the original version of NSQ was translated into Turkish by five qualified individuals who are proficient in English and Turkish. After the initial translation was carried out, the instrument was edited and reviewed again by researchers; as a result, the adapted version of the scale had 47 items.

The pilot study for the Turkish version of the scale was performed with data gathered from 228 instructors working at four universities in Ankara. In order to determine the underlying factor structure of NSQ items, the data were subjected to EFA with principal axis factoring and oblique rotation. In the first analysis, the extraction was made on eigenvalue larger than 1 , scree plot, and percentage of variance (Tabachnick \& Fidel, 2007). Parallel to the original structure of NSQ, the extraction was forced for three factors. The results suggested that three dimensions account for $47.34 \%$ of the total variance. Once the initial structure for the adapted NSQ was identified with EFA, confirmatory factor analysis (CFA) was conducted in order to provide further construct validation for the factor structure of the adapted NSQ with another data set collected from a larger population in the main study. After one modification, the CFA results of the final model indicated significant results $(\chi 2=6209.580, d f=1020, p=.00$; CFI=.77; NNFI=.75; RMSEA=.08) with mediocre fit for RMSEA (Browne and Cudeck, 1993) and good fit for CFI and NNFI (Hu \& Bentler, 1999) indices. 


\section{Organizational Commitment Scale}

This scale was originally developed by Meyer, Allen, and Smith (1993) with 24 items measuring affective, continuance and normative commitment to the organization. Meyer et al. (1993) reported the reliability values as .82 for the affective component, .83 for the normative component, and .74 for the continuance component of the scale. The scale was translated and adapted to Turkish by Wasti (2003), in which she reported reliability values of .84 for the affective component, .82 for the normative component, and .70 for the continuance component of the scale with a total of 33 items. In this study the CFA results of the final analysis indicated significant chi-square value $(\chi 2=3251.054, d f=489, p=.00)$ with the comparative fit index (CFI) value of .78, non-normed fit index (NNFI) value of .77, and root mean square error of approximation (RMSEA) value of .08. Considering RMSEA value of .08 , the second analysis resulted in mediocre model fit, (Browne \& Cudeck, 1993). Thus, CFA results of the final model added further evidence on the construct validity of OCS. The reliability of Organizational Commitment Scale is .90 for affective commitment, .91 for normative commitment, and .66 for continuance commitment, and the item total correlation values range between -.59 and .67 .

\section{Teachers' Sense of Efficacy Scale}

This scale is the Turkish version of the Teachers' Sense of Efficacy Scale of Çapa-Aydın, Çakıroğlu, \& Sarıkaya (2005), which was originally developed by Tschannen-Moran and Woolfolk-Hoy (2001). The scale measures to what extent instructors feel themselves capable of dealing with educational and psychological needs of their students, as well as structuring appropriate academic activities in the classroom, and dealing with difficult students causing discipline problems and violating the rules. Tschannen-Moran and Woolfolk Hoy's (2001) instrument, developed in a seminar at Ohio University, had 24 items with a 9-point rating scale (1= Nothing, 9= A Great Deal), and it was investigated by Tschannen-Moran and her colleagues in various studies (Çapa- Aydın et al., 2005). Tschannen-Moran and Woolfolk-Hoy (2001) named these three subscales, each with 8 items, as Efficacy for Instructional Strategies, Efficacy for Classroom Management and Efficacy for Student Engagement. The reliability for the whole scale was .94 and the reliabilities of the subscales were .91 for Efficacy for Instructional Strategies, .90 for Efficacy for Classroom Management, and .87 for Efficacy for Student Engagement.

In this study as given in Table 1, the reliability of Teachers' Sense of Efficacy Scale is .79 for efficacy for student engagement, .91 for efficacy for instructional strategies, and . 82 for efficacy for classroom management, and the item total correlation values range between .07 and .70. CFA was conducted with the data in the main study in order to provide further evidence on the construct validity of the scale. In this study the results of CFA showed that chi-square value was significant $(\chi 2=1654.928$, $d f=249, p=.00$ ) with the comparative fit index (CFI) value of .88, non-normed fit index (NNFI) value of .86 , and root mean square error of approximation (RMSEA) value of .08. As the criterion value of RMSEA was taken into consideration, the CFA indicated mediocre fit (Browne \& Cudeck, 1993). Thus, CFA results added further evidence on the construct validity of TSES.

\section{Data Analysis}

As this study sought to explore relationship between predictor and criterion variables and designed as a correlational research, inferential statistics were used in this study in order to investigate the relationship between various organizational and individual level variables, and organizational socialization. Three separate hierarchical regression analyses were carried out for organization socialization, department socialization, and task socialization, after the related assumptions were validated. The variables were entered in seven blocks. 


\section{Results}

\section{Descriptive Statistics}

The results of descriptive statistics, correlation matrix and reliability scores are presented in Table 1. The correlation scores suggest that the correlations between variable pairs are moderate which indicates that multicollinearity is not an issue for the regression analyses.

\section{Regression Analyses}

Before running the hierarchical regression analysis, the required assumptions of multicollinearity, normality of errors, homoscedasticity, independence of errors, and influential observations suggested by Field (2009) and Hair, Black, Babin, and Anderson (2010) were checked and validated for three analysis separately. A slightly distorted but bell-shaped figure was observed when the histogram was inspected visually. Histogram and P-P Plot of the residual were checked in order to test for normality of residuals. Besides, despite slight deviations from the normal distribution, P-P plot also represented normal distribution for the residuals. Thus, the assumption of normality of residuals was validated. The residual scatterplot was checked for linearity and homoscedasticity. The overall shape of the scatterplot is expected to be in the form of a rectangle if there is linearity (Tabachnick \& Fidell, 2007). It was observed that the shape of the scatterplot could be considered to represent a rectangle despite some misfits. Thus, linearity assumption was validated for this analysis. Considering the validation of the homoscedasticity assumption, the points need to be randomly and uniformly dispersed throughout the plot (Field, 2009). Although the variance of residuals decreases towards the right side of the plot, the points in the residual scatterplot are randomly dispersed; thus, it was concluded that the assumption of homoscedasticity is validated. Three different ways were suggested by Field (2009) for multicollinearity check. One is scanning the correlation matrix to check whether a high correlation, i.e. correlations above .90 , exits between the predictor variables. No substantial correlations ( $r>.90)$ were observed between predictors in the correlation matrix; thus, multicollinearity assumption was validated. Checking VIF and tolerance values are the other two ways to validate multicollinearity assumption. The findings showed that VIF values are dispersed between 1.009 and 3.735 and that tolerance values range from .268 to .991 . Since the criteria values less than 5 for VIF, greater than .20 for tolerance (1/VIF) are regarded acceptable (Menard, 1995), the assumption of multicollinearity was concluded to be validated. The results of the hierarchical regression analyses for organization, department and task socialization are displayed in Table 2.

\section{Organization Socialization}

Since the variable university type is a categorical variable dummy codes were created before step 1 in regression analysis. In the dummy coding 0 was assigned to public university and 1 was assigned to other categories in the variable.

Step 1 included background variables which were university type, academic degree, and years of teaching experience. After step 1, the regression model was significant, $R^{2}=.02, \Delta F(4,538)=3.30$. University type $(\beta=-.11 ; \mathrm{t}=-2.61 ; \mathrm{p}<.05)$ was a significant predictor of organization socialization in favor of private university. After adding three variables, which were pre-service, in-service training, and mentoring, in step 2 , the regression model was again significant, $R^{2}=.05, \Delta F(3,535)=4.23$. Although the model was significant, adding training variables resulted only in $2 \%$ increment in the total variance explained. In step 2 , mentoring $(\beta=-.16 ; \mathrm{t}=3.54 ; \mathrm{p}<.01)$ was a significant predictor of organization socialization, while pre-service and in-service training were not. After step 3 , with the addition of salary, personnel rights, social, health, and sports facilities, the regression model was significant, $R^{2}=.15, \Delta F$ $(5,530)=8.31$ with $7 \%$ increment in the total variance explained in the model. Salary $(\beta=-.17 ; t=-2.26$; $\mathrm{p}<.05)$ and personnel rights $(\beta=.25 ; \mathrm{t}=3.29 ; \mathrm{p}<.01)$ were significant predictors of organization socialization with the $15 \%$ increment in the total variance explained. In step 4 , knowledge sharing was added to the model. After step 4, the regression model was again significant; $R^{2}=.27, \Delta F(1,529)=108.9$. Knowledge sharing $(\beta=.43 ; \mathrm{t}=10.43 ; \mathrm{p}<.01)$ was a significant predictor for organizational socialization and resulted in $15 \%$ additional variance explained in the model. After step 5 , in which job satisfaction was entered into the model, the regression model was still significant, $R^{2}=.29, \Delta F(1,528)=18.05$, and 
job satisfaction $(\beta=.18 ; \mathrm{t}=4.25 ; \mathrm{p}<.01)$ was a significant predictor for organizational socialization; however, it contributed to the total variance explained only by $2 \%$. In step 6 , commitment variables entered into the model. After step 6, the regression model was significant; $R^{2}=.31, \Delta F(3,525)=3.61$; however, affective commitment $(\beta=.16 ; \mathrm{t}=2.52 ; \mathrm{p}<.05)$ was a significant predictor of organization socialization with a minimum contribution to the total variance explained in the model (1\%). In the final step, efficacy variables were entered into the model and the model was significant; $R^{2}=.36, \Delta F(3,522)=$ 14.51. Adding the efficacy variables resulted in $5 \%$ increment in the total variance explained. In step 7 , efficacy in instructional strategies $(\beta=.20 ; \mathrm{t}=3.22 ; \mathrm{p}<.01)$ was a significant predictor of organization socialization.

\section{Department Socialization}

Step 1 included background variables which were university type, academic degree, and years of teaching experience. After step 1, the regression model was not significant. After adding the training variables in step 2, the regression model was significant; $R^{2}=.06, \Delta F(3,519)=9.35$. Training variables resulted in $5 \%$ increment in the total variance explained. Pre-service training $(\beta=-.15 ; \mathrm{t}=-3.35 ; \mathrm{p}<.01)$, in-service training $(\beta=-.13 ; \mathrm{t}=2.83 ; \mathrm{p}<.01)$, and mentoring $(\beta=-.15 ; \mathrm{t}=3.25 ; \mathrm{p}<.01)$ were significant predictors for department socialization. In step 3 , variables on workplace benefits were entered into the model. After step 3, the model was significant, $R^{2}=.17, \Delta F(5,514)=13.49$, with $11 \%$ increment in the total variance. Personnel rights $(\beta=-.24 ; \mathrm{t}=3.15 ; \mathrm{p}<.01)$ and social facilities $(\beta=-.13 ; \mathrm{t}=1.98 ; \mathrm{p}<.01)$ were significant predictors of department socialization. In step 4, knowledge sharing was entered to the model. After step 4, the regression model was significant, $R^{2}=.38, \Delta F(1,513)=172.66$. Knowledge sharing $(\beta=-.51 ; \mathrm{t}=13.14 ; \mathrm{p}<.01)$ was a significant predictor for department socialization and contributed $21 \%$ to the total variance explained in the model. 


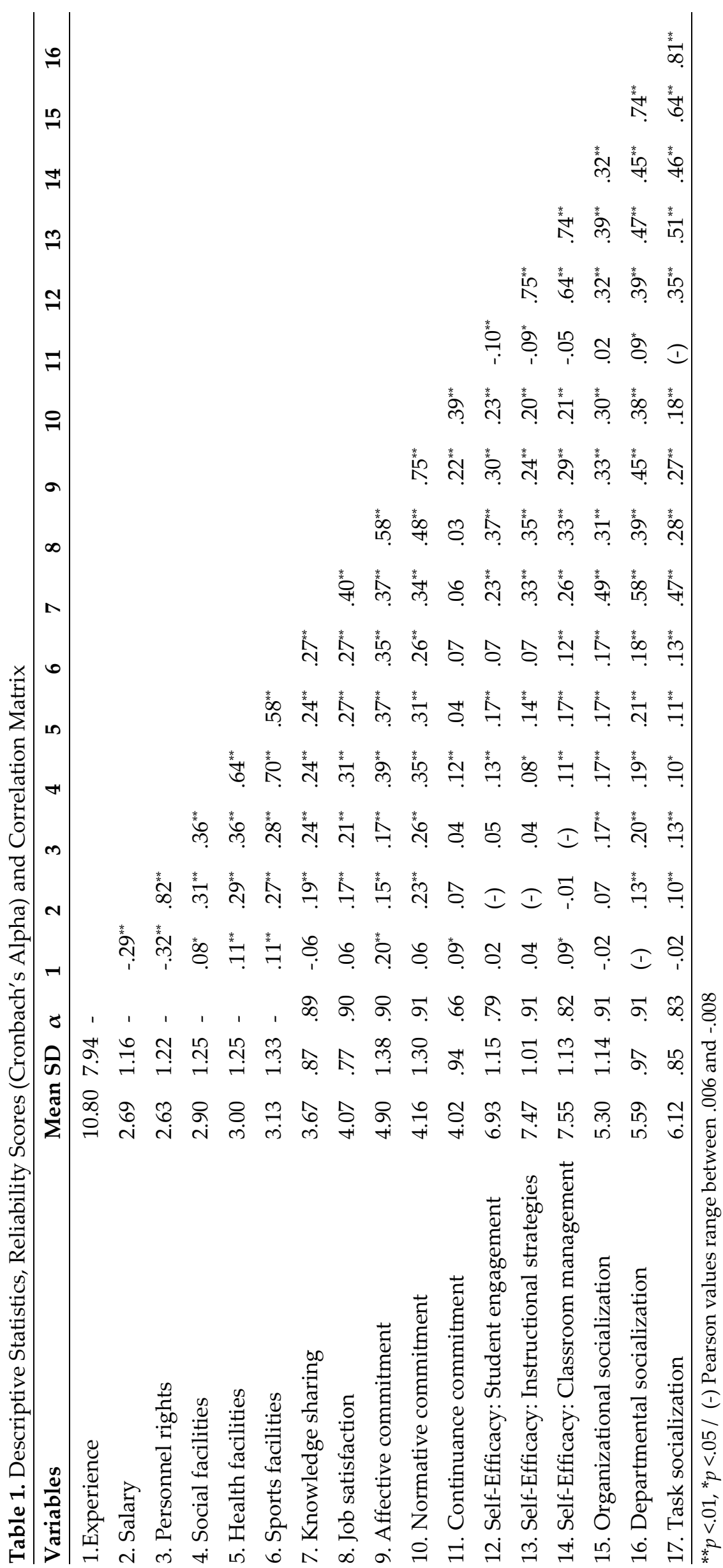


In step 5 , job satisfaction was added to the model and the regression model was still significant, $R^{2}=.42, \Delta F(1,512)=34.07$. Job satisfaction $(\beta=-.23 ; \mathrm{t}=5.84 ; \mathrm{p}<.01)$ was a significant predictor of department socialization and resulted in $4 \%$ increment in the total variance explained in the model. After step 6, in which commitment variables were entered into the model, the model was again significant; $R^{2}=.46, \Delta F(3,509)=13.89$ with additional $4 \%$ increment in the total variance explained in the model. Affective commitment $(\beta=-.32 ; \mathrm{t}=5.65 ; \mathrm{p}<.01)$ was a significant predictor of organization socialization. After step 7, the regression model was significant, $R^{2}=.53, \Delta F(3,506)=23.92$. Efficacy variables resulted in $8 \%$ increment in the total variance explained. Efficacy in instructional strategies $(\beta$ $=-.13 ; \mathrm{t}=2.42 ; \mathrm{p}<.05)$ and classroom management $(\beta=-.14 ; \mathrm{t}=3.04 ; \mathrm{p}<.01)$ were significant predictors of department socialization.

\section{Task Socialization}

Step 1, when background variables entered into the model, the regression model was not significant, $R^{2}=.01, \Delta F(4,536)=1.56$. However, in this set university type $(\beta=-.10 ; \mathrm{t}=-2.29 ; \mathrm{p}<.05)$ was a significant predictor of task socialization. In step 2, training variables were added to the model and the model was significant; $R^{2}=.04, \Delta F(3,533)=5.71$, and the training variables added $3 \%$ to the total variance explained in the model. Among the training variables, pre-service $(\beta=-.12 ; \mathrm{t}=-2.74 ; \mathrm{p}<.01)$ and in-service training $(\beta=.14 ; \mathrm{t}=3.11 ; \mathrm{p}<.01)$ were significant predictors of task socialization. After step 3, with the addition of variables on the workplace benefits, the regression model was significant; $R^{2}=.09, \Delta F(5,528)=5.70$, which resulted $5 \%$ increment in the total variance explained. Among the variables, sports facilities $(\beta=.15 ; \mathrm{t}=2.49 ; \mathrm{p}<.05)$ was a significant predictor of task socialization. In step 4 , knowledge sharing was entered into the model and the model was significant; $R^{2}=.24, \Delta F(1,527)=$ 104.59 , and knowledge sharing $(\beta=.43 ; \mathrm{t}=10.22 ; \mathrm{p}<.01)$ was a significant predictor of task socialization and resulted in $15 \%$ increment in the total variance explained. In step 5 , job satisfaction was entered into the model and the regression model was $\Delta \mathrm{R}^{2}=\mathrm{R}$ square change referring to the increment in the total variance explained each step significant; $R^{2}=.26, \Delta F(1,527)=13.43$, and job satisfaction $(\beta=.16 ; \mathrm{t}=3.66$; $\mathrm{p}<.01$ ) was a significant predictor of task socialization and resulted in $2 \%$ increment in the total variance explained. In step 6 commitment variables were entered into the model and model was still significant, $R^{2}=.28, \Delta F(3,523)=4.20$. Commitment variables resulted in $2 \%$ increment in the total variance explained. Affective commitment $(\beta=.21 ; \mathrm{t}=3.29 ; \mathrm{p}<.01)$ and normative commitment $(\beta=-.13 ; \mathrm{t}=-2.13$; $\mathrm{p}<.01)$ were significant predictors of task socialization. In the final step, variables of efficacy belief were entered into the model and the model was still significant, $R^{2}=.44, \Delta F(3,523)=51.56$. Efficacy belief variables resulted in $17 \%$ increment in the total variance explained. Efficacy in instructional strategies $(\beta=.40 ; \mathrm{t}=6.65 ; \mathrm{p}<.01)$ and Efficacy in classroom management $(\beta=-.16 ; \mathrm{t}=3.32 ; \mathrm{p}<.01)$ were significant predictors of task socialization. 
Table 2. Summary of Hierarchical Regression Analyses for Organization, Department and Task Socialization

\begin{tabular}{|c|c|c|c|c|c|c|c|c|c|c|c|c|}
\hline \multirow[b]{2}{*}{ Predictor variable } & \multicolumn{4}{|c|}{$\begin{array}{l}\text { Organization } \\
\text { Socialization }\end{array}$} & \multicolumn{4}{|c|}{$\begin{array}{l}\text { Department } \\
\text { Socialization }\end{array}$} & \multicolumn{4}{|c|}{$\begin{array}{c}\text { Task } \\
\text { Socialization }\end{array}$} \\
\hline & B & SE & $\beta$ & $t$ & B & SE & $\beta$ & $t$ & B & SE & $\beta$ & $\mathbf{t}$ \\
\hline \multicolumn{13}{|c|}{ Step 1 Background variables } \\
\hline University type & -.33 & .13 & -.11 & $-2.61^{* *}$ & -.20 & .11 & -.08 & -1.90 & -.22 & .09 & -.10 & $-2.29^{*}$ \\
\hline Education & -.12 & .10 & -.05 & -1.19 & $(-)$ & .09 & $(-)$ & .10 & -.04 & .07 & -.02 & -.49 \\
\hline Work experience & .01 & .01 & .07 & .87 & $(-)$ & .01 & $(-)$ & $(-)$ & $(-)$ & $(-)$ & -.07 & -.88 \\
\hline \multicolumn{13}{|l|}{ Step 2 Training } \\
\hline Pre-service & -.08 & .10 & -.03 & -.77 & -.29 & .09 & -.15 & $-3.35^{* *}$ & -.21 & .08 & -.12 & $-2.74^{* *}$ \\
\hline In-service & -.02 & .11 & - & -.21 & .27 & .10 & .13 & $2.83^{* *}$ & .26 & .08 & .14 & $3.11^{* *}$ \\
\hline Mentoring & .40 & .11 & .16 & $3.54^{* *}$ & .32 & .10 & .15 & $3.25^{* *}$ & .11 & .09 & .06 & 1.34 \\
\hline \multicolumn{13}{|c|}{ Step 3 Workplace benefits } \\
\hline Salary & -.16 & .07 & -.17 & $-2.26^{*}$ & -.10 & .06 & -.12 & -1.69 & -.05 & .05 & -.07 & -.98 \\
\hline Personnel rights & .24 & .07 & .25 & $3.29^{* *}$ & .19 & .06 & .24 & $3.15^{* *}$ & .10 & .05 & .15 & 1.87 \\
\hline Social facilities & .09 & .06 & .10 & 1.55 & .10 & .05 & .13 & $1.98^{* *}$ & .03 & .05 & .05 & .67 \\
\hline Health facilities & .04 & .05 & .04 & .69 & .06 & .04 & .07 & 1.30 & $(-)$ & .04 & $(-)$ & -.08 \\
\hline Sports facilities & .06 & .05 & .07 & 1.20 & .07 & .04 & .09 & 1.52 & .10 & .04 & .15 & $2.49^{*}$ \\
\hline \multicolumn{13}{|l|}{ Step 4} \\
\hline Knowledge sharing & .56 & .05 & .43 & $10.43^{* *}$ & .57 & .04 & .51 & $13.14^{* *}$ & .44 & .04 & .43 & $10.22^{* *}$ \\
\hline \multicolumn{13}{|l|}{ Step 5} \\
\hline Job Satisfaction & .26 & .06 & .18 & $4.25^{* *}$ & .28 & .05 & .23 & $5.84^{* * *}$ & .17 & .05 & .16 & $3.66^{* *+}$ \\
\hline \multicolumn{13}{|l|}{ Step 6 Commitment } \\
\hline Affective & .14 & .05 & .16 & $2.52^{*}$ & .23 & .04 & .32 & $5.65^{* *}$ & .13 & .04 & .21 & $3.29^{* * *}$ \\
\hline Normative & .01 & .05 & .01 & .19 & -.04 & .04 & -.05 & -.87 & -.09 & .04 & -.13 & $-2.13^{* *}$ \\
\hline Continuance & -.05 & .05 & -.04 & -.93 & $(-)$ & .04 & $(-)$ & -.04 & -.04 & .04 & -.04 & -.93 \\
\hline \multicolumn{13}{|c|}{ Step 7 Efficacy beliefs } \\
\hline Student engagement & .05 & .06 & .05 & .97 & .04 & .04 & .05 & 1.05 & -.08 & .04 & -.11 & $-2.04^{* *}$ \\
\hline $\begin{array}{l}\text { Instructional } \\
\text { strategies }\end{array}$ & .23 & .07 & .20 & $3.22^{* *}$ & .13 & .05 & .13 & $2.42^{*}$ & .33 & .05 & .40 & $6.65^{* *}$ \\
\hline $\begin{array}{l}\text { Classroom } \\
\text { management }\end{array}$ & .02 & .05 & .02 & .45 & .12 & .04 & .14 & $3.04^{* *}$ & .12 & .04 & .16 & $3.32^{* *+}$ \\
\hline Model Summary & $\mathbf{R}$ & $\mathbf{R}^{2}$ & $\Delta \mathbf{R}^{2}$ & $\Delta \mathrm{F}$ & $\mathbf{R}$ & $\mathbf{R}^{2}$ & $\Delta \mathbf{R}^{2}$ & $\Delta \mathbf{F}$ & $\mathbf{R}$ & $\mathbf{R}^{2}$ & $\Delta \mathbf{R}^{2}$ & $\Delta \mathrm{F}$ \\
\hline Step 1 & .16 & .02 & .02 & $3.30^{*}$ & .09 & $(-)$ & $(-)$ & 1.01 & .11 & .01 & .01 & 1.56 \\
\hline Step 2 & .25 & .05 & .02 & $4.23^{* *}$ & .24 & .06 & .05 & $9.35^{* *}$ & .21 & .04 & .03 & $5.71^{* *}$ \\
\hline Step 3 & .34 & .15 & .07 & $8.31^{* *}$ & .41 & .17 & .11 & $13.49^{* *}$ & .30 & .09 & .05 & $5.70^{* *}$ \\
\hline Step 4 & .52 & .27 & .15 & $108.9^{* *}$ & .61 & .38 & .21 & $172.66^{* *}$ & .49 & .24 & .15 & $104.59^{* *}$ \\
\hline Step 5 & .54 & .29 & .02 & $18.05^{* *}$ & .65 & .42 & .04 & $34.07^{* *}$ & .51 & .26 & .02 & $13.43^{* *}$ \\
\hline Step 6 & .55 & .31 & .01 & $3.61^{*}$ & .68 & .46 & .04 & $13.89^{* * *}$ & .53 & .28 & .02 & $4.20^{* *}$ \\
\hline Step 7 & .60 & .36 & .05 & $14.51^{* *}$ & .73 & .53 & .08 & $23.92^{* *}$ & .67 & .44 & .17 & $51.56^{* *}$ \\
\hline
\end{tabular}




\section{Discussion and Conclusion}

The results of hierarchical regression analysis documented the predictive value of various organizational (training, work conditions, knowledge sharing) and individual (academic degree, teaching experience, length of employment at current work place, job satisfaction, commitment, selfefficacy) for organizational, department, and task socialization. Considering the background variables, type of university as public or private significantly predicted organization socialization and task socialization, but it did not predict department socialization. This could be explained by the fact that public universities offer better job security. In a private university, employment contract is renewed on a yearly basis, generally based on performance. In literature, there is inconsistency about the impact of this variable. For example, some scholars reported poor commitment on the part of private sector employees (e.g., Moon, 2000; Zeffane, 1994) while some other scholars reported high commitment for private sector employees (e.g., Balfour \& Wechsler, 1990). Still some other studies reported no difference (e.g., Steinhaus \& Perry, 1996).

In addition, the training variables were significant predictors for socialization. This is consistent with the related studies in literature. For example, Bauer et al. (2007), and Saks, Uggerslev, and Fassina (2007) found that training and mentoring are the strongest predictors of job satisfaction, organizational commitment, and retention. The results of this study indicated that having mentor significantly predicted socialization to the organization and to the department. Likewise, Allen, McManus, and Russell (1999) found that mentoring contributes to the successful socialization of newcomers and improves their performance. It was suggested in the same study that mentors can help newcomers learn to become an effective and efficient member of the group. In another study about the relation between mentoring and socialization, Cawyer, Simonds, and Davis (2002) found that mentoring relationships help the new comers to develop and professional knowledge and skills in the new organization setting.

The results of this study indicated that having in-service training significantly predicted socialization to the department and to the task, but surprisingly, having had pre-service training significantly predicts socialization to the department and to the task in a negative direction. High sense of self-efficacy of instructors seems to be the only explanation for this negative relation. Referring to the findings of Gist, Stevens, and Bavetta (1991) about the relation between training, efficacy, and socialization, training of newcomers may not be equally effective for all newcomers since it depends on newcomers' level of self-efficacy.

Considering work condition variables in the model, it was found that salary and personnel rights significantly predicted socialization to the organization, but there is a negative relation between salary and socialization to the organization; personnel rights and social facilities significantly predicted socialization to the department; sports facilities significantly predicted socialization to the task. The fact that financial incentives make an employee highly motivated to their job and organization may explain the relation between the predictors of financial incentives, and socialization to the organization and socialization to the department. However, this contradicts with the negative relation between salary and socialization to the organization. This calls for further research in this regard. Since the majority of participants in this study are females, availability of kindergarten is crucial, which may explain the relation between social facilities and socialization to the department. Furthermore, the fact that healthy life style and being fit is the current trend may explain the relation between the availability of sports facilities and socialization to the task. However, the fact that the availability of social facilities significantly predicts socialization to the department and the availability of sports facilities significantly predicts socialization to the task need to be investigated in further research. 
The results indicated that knowledge sharing explained the maximum percentage of the variance in all three types of socialization. This finding is parallel to the previous studies in literature. For example, review of antecedents and outcomes of socialization, Bauer et al. (2007) reported that information gathering, which could be realized through the availability of knowledge sharing, is a significant antecedent of socialization. Knowledge means reduced uncertainty (Iqbal, Toulson, \& Tweed, 2011) and contributes to self-socialization (Tidwell \& Sias, 2005).

As for job satisfaction variable in the model, hierarchical regression analysis results showed that job satisfaction is a significant predictor of socialization. Thus, it can be concluded that instructors who are highly satisfied with their job are better socialized. In their study about the changes in job satisfaction over time, Boswell, Shipp, Payne, and Culbertson (2009) concluded that change pattern of job satisfaction depends on previous job experience and fulfillment of commitments, adding that newcomers' job satisfaction makes a peak after the entry, but drops down and remain steady afterwards. Boswell et al. (2009) found that experiencing less or more socialization is a critical factor in this sense; and socialization to the work setting contribute to great extend to exhibit positive reaction to the work setting and the job itself.

Considering organizational commitment variables, the findings in this study indicated that affective commitment significantly predicted socialization to the organization, to the department, and to the task. However, the majority of studies in literature related to commitment indicate commitment as an outcome of socialization. For example, Wiener (1988) theorized commitment to be an outcome of socialization. Additionally, Caldwell, et al. (1990) found that when there are carefully conceived and implemented socialization practices, employees demonstrate higher committed to organizational values. Also, Allen and Meyer (1990) concluded in their study that cultural socialization is antecedent to commitment. However, contrary to these research results, the finding in this study that affective commitment significantly predicted socialization makes sense. The items related to affective commitment in the scale used in this study involves the individual's attachment to, identification with, and involvement in the organization. It could be concluded that when individuals are high in this commitment, they will be motivated to learn more about the organization, department, and task; thus, better socialized.

The findings of this study also indicated that normative commitment significantly but negatively predicted task socialization. Wiener (1982, p. 421) defined commitment as "the totality of internalized normative pressures to act in a way that meets organizational interests." Ok $(2007$, p. 7) commented on Wiener's definition stating that "according to this definition, commitment is a moral construct, and it is proposed that one's commitment to the organization is determined by pre-and postemployment socialization referring that commitment initially develops as a result of socialization in a specific culture and family and then in the organization. This view of commitment refers to the normative commitment."

Finally, the results of this study indicated that self-efficacy for instructional strategies and selfefficacy for classroom management significantly predicted task socialization while self-efficacy for student engagement significantly but negatively predicted socialization to the task. The items in the scale related to self-efficacy for instructional strategies and classroom management indicate how competent, resourceful and knowledgeable instructors regard themselves as a teacher, and how capable they are in providing ideal teaching environment in the classroom, and dealing with difficult students and discipline problems. Instructors' higher level of confidence in these respects shall indicate their socialization to the task. Surprisingly, instructors' self-efficacy for student engagement predicted task socialization in a negative way. Items in the scale for this dimension had questions related to pedagogical aspect of teaching, like motivating students; thus, a possible explanation could be that instructors who feel less secure about student engagement efficacy could attempt to be more socialized to the task to compensate for this. Another possible explanation could be that in more autonomous learning environment at university, instructors' priority for efficacy is not motivating them; however, this still calls for further research in this regard. 


\section{Implications for Practice}

With regard to practice, among the individual level factors, which are academic degree, teaching experience, length of employment at current work place, job satisfaction, commitment, and self-efficacy, job satisfaction is the best predictor of socialization to the organization and to the department, while it is the second best predictor of socialization to the task. The self-efficacy for instructional strategies is the best predictor of task socialization. Therefore, practitioners should focus on finding out ways for encouraging and increasing knowledge sharing both in the organization and in the department, and increasing job satisfaction among instructors since they seem to be critical variables in predicting how well instructors are socialized in all these dimensions, which in turn, shall determine how less likely they are to leave their job voluntarily, and how high likely to exhibit greater productivity (Kramer, 2010; Schein, 1985).

Additionally, self-efficacy of instructors for instructional strategies could be increased through appropriate training programs in order to make instructors feel competent, resourceful and knowledgeable as a teacher. Training programs, whether in the form of pre-service, in-service or mentoring, also predict all dimensions of socialization significantly. However, practitioners should consider the self-efficacy beliefs of instructors while designing training programs since those with low self-efficacy need more guidance during training programs, and certain methods of training may have limited value for instructors with strong self-efficacy (Gist et al., 1991).

Another important point is that affective commitment of instructors significantly predicts their organizational socialization. Since affective commitment, also expressed as emotional tie with their organization and its goals, practitioners should consider implementing the management and leadership style that would lead to increasing affective commitment. The motivation to uphold membership in an organization stems from work experiences; and employees who have a strong affective commitment maintain their employment because of a strong internal desire (Ünüvar, 2006). Besides, they think the management and the leader is fair to them. Still another important point is related to instructors' feeling of resentment about not being esteemed highly enough in the academic environment. Compared to socialization to their department and task, instructors are less socialized to the organization. In this respect, practitioners should take necessary measures to get instructors involved in issues outside the department within the university, which would decrease the feeling of alienation and increase the feeling of ownership for the university-wide issues. Furthermore, it was noted in this study that instructors are socialized to the organization not because of the salary. Since non-material incentives seem to matter to contribute to socialization, practitioners should find ways to create opportunities to emphasize appreciation of instructors' work, and to make them feel the respectable aspect of being a teacher and working at a university.

In Turkish higher education flagship universities have recognized the importance of the socialization process and they initiated socialization programs including a wide content and distributed throughout the first two years of the newcomers in their new work setting. For example, the training program at the Middle East Technical University covers cultural knowledge on the history of the university, technical knowledge (e.g., rules and regulations, funds, administrative processes), and academic knowledge (e.g., improving teaching and student assessment skills and knowledge). The current trend in Turkey suggests that Turkish universities will continue to invest in the socialization of their faculty in the form of formal programs.

In this study, self-efficacy for instructional strategies and classroom management significantly predicted department socialization while self-efficacy for instructional strategies significantly predicted socialization to the organization. This seems to be in line with other studies in literature. For example, Bauer et al. (2007) concluded that self-efficacy has a mediator role between socialization efforts by the organization and task performance. The results of the same study also suggested that newcomers whose sense of self-efficacy is high show confidence in going beyond the existing formal definition of their roles and position in the organization, from which it could be concluded that those with high sense of self-efficacy are inclined to the organization and the department more smoothly. 


\section{Limitations of The Study}

Three main limitations are associated with the current study. Firstly, in this study it was assumed that the independence of the residuals (errors); however, there might be a dependence between the residuals because of the fact that the participants do not come from different universities. The participants are members of 10 different universities which means that the data set compose groups and each group work at the same university. Secondly, cluster sampling data collection method was used in the study. The external validity being reduced, the results do not represent all English instructors of Turkish universities although careful attention was given to make sure underlying assumptions of multiple linear regression were met, which is a condition for generalizability. Thirdly, the data were collected from 16 different universities under varying physical conditions. Thus, the location can be an internal validity threat for the study. Subject characteristics can be another internal validity threat as the age of participants varied between 21 and 66, and the years of experience as a teacher ranged from $1 / 2$ to 43 years. Such differences among the participants could be a limitation for the study. Despite such differences in age and experience, the sample can be considered as a homogenous group, since it is made up of instructors working at preparatory schools, which can be another internal validity threat. The use of self-report measures is another limitation related to the data in the study, which may lead to inflation of common method variance. Also, data for both dependent and independent variables were collected at the same time, which may be a reason for inflation of common variables.

\section{Future Research}

Considering the shortcomings of this study, some recommendations are advanced for future studies. Firstly, in the present study, data were collected from 4 cities in Turkey, and one city in Turkish Republic of Northern Cyprus. Further studies can collect data from a wider geographical area in Turkey, including the Eastern and Northern regions, which will provide a better insight about the predictors of socialization. Additionally, this study was designed as a quantitative research; however, qualitative research studies could be conducted to have a better understanding of the process of socialization. Furthermore, although this study examined predictors of organizational socialization considering a number of both organizational and individual variables, there may be other alternative variables important for socialization, such as collective efficacy, medium of instruction at the university as Turkish or English, and length of time instructors have the same class of students during the academic year. What instructors think about the ability of the team and the faculty of teachers in the department may influence their self-efficacy beliefs, which may also influence their socialization. Additionally, this study included instructors from both English medium and Turkish medium universities, which may be another variable affecting the level of socialization. However, English-medium of university or Turkishmedium university was not included in this study as a variable. Further studies need to explore this variable.

Finally, more studies need to be carried out with data collected from different populations to ensure the validity of the Turkish adaptation of Organizational Socialization Scale (OSS), as well as using another socialization scale in which specific content areas of socialization are identified independently. CFA results of Turkish adaptation of OSS barely provided mediocre fit, which may result from the fact that the participants in this study formed a rather homogeneous group, each being an English instructor at university. A similar problem is also noted with the Organizational Commitment Scale (OCS). CFA results of OCS barely provided mediocre fit, and reliability of continuance commitment sub-scale is rather low. Also, though few in number, there are some rather low factor loadings. Wasti (2003) stated that there are theoretical and methodological problems both with the original scale and the Turkish adaptation, adding that lack of alternatives and high perceived costs show better fit in CFA as two separate concepts, and that lack of alternatives needs to be considered as an antecedent of organizational commitment. More studies need to be carried out regarding theoretical and methodological problems with the OCS. 


\section{References}

Allen, N. J., \& Meyer, J. P. (1990). The measurement and antecedents of affective, continuance and normative commitment to the organization. Journal of Occupational Psychology, 63, 1-18. doi:10.1111/j.2044-8325.1990.tb00506.x

Allen, T. D., McManus, S. E., \& Russell, J. E. (1999). Newcomer socialization and stress: Formal peer relationships as a source of support. Journal of Vocational Behavior, 54, 453-470. doi:10.1006/jvbe.1998.1674

Angelides, P., \& Mylordou, A. (2011). The beneficial outcome of a successful mentoring relationship: The development of inclusive education. Teacher Development, 15(4), 533-547.

Ashford, S. J., \& Cummings, L. L. (1985). Proactive feedback seeking: The instrumental use of the information environment. Journal of Occupational Psychology, 58, 61-79.

Balfour, D. L., \& Wechsler, B. (1990). Organizational commitment: A reconceptualization and empirical test of public-private difference. Review of Public Personnel Administration, 10, $23-40$.

Bandura, A. (1986). Social foundations of thought and action: A social cognitive theory. Englewood Cliffs, NJ: Prentice-Hall.

Bandura, A. (1997). Self-efficacy: The exercise of control. New York: W. H. Freeman and Company.

Bandura, A., \& Wood, R. E. (1989). Effect of perceived controllability and performance standards on self-regulation of complex decision-making. Journal of Personality and Social Psychology, 56, 805-814.

Bauer, T. N., Bodner, T., Erdogan, B., Truxillo, D. T., \& Tucker, J. S. (2007). Newcomer adjustment during organizational socialization: A meta-analytic review of antecedents, outcomes, and methods. Journal of Applied Psychology, 92, 707-721. doi:10.1037/0021-9010.92.3.707

Birnbaum, R. (1988). How colleges work: The cybernetics of academic organizations and leadership. San Francisco: Jossey-Bass.

Boswell, W. R., Shipp, A. J., Payne, S. C., \& Culbertson, S. S. (2009). Changes in newcomer job satisfaction over time: Examining the pattern of honeymoons and hangovers. Journal of Applied Psychology, 94(4), 844-858. doi:10.1037/a0014975

Boyer, E. L., Altbach, P. G., \& Whitelaw, M. J. (1994). The academic profession: An international perspective. Princeton, NJ: Carnegie Foundation for the Advancement of Teaching.

Browne, M. W., \& Cudeck, R. (1993). Alternative ways of assessing model fit. In K. A. Bollen, \& J. S. Long (Eds.), Testing Structural Equation Models (pp. 136-162). Newbury Park, CA: Sage.

Caldwell, D. F., Chatman, J. A., \& O'Reilly, C. A. (1990). Building organizational commitment: A multifirm study. Journal of Occupational Psychology, 63(3), 245-261.

Cawyer, C. S., Simonds, C., \& Davis, S. (2002). Mentoring to facilitate socialization: The case of the new faculty member. Qualitative Studies in Education, 15(2), 225-242. doi:10.1080/09518390110111938

Chao, G. T., O'Leary-Kelly, A. M., Wolf, S., Klein, H. J., \& Gardner, P. D. (1994). Organizational socialization: Its content and consequences. Journal of Applied Psychology, 79(5), 730-743.

Chatman, J. A. (1991). Matching people and organizations: Selection and socialization in public accounting firms. Administrative Science Quarterly, 35, 459-484

Çapa-Aydın, Y., Çakıroğlu, J., \& Sarıkaya, H. (2005). The development and validation of a Turkish version of the teachers' sense of efficacy scale. Education and Science, 30(137), 74-81.

Coladarci, T. (1992). Teachers' sense of effficacy and commitment to teaching. Journal of Experimental Education, 60, 323-337.

Dewitte, H., \& De Cuyper, N. (2003). Towards a positive perspective on well-being: Investigating the positive engagement of the Flemish employee. In W. Herremans (Ed.), The Flemish Labour Market: Report Flemish Labour Market Day (pp. 115-138). Leuven: LeuvenUniversity Press. 
Feldman, D. C. (1989). Socialization, resocialization, and training: Reframing the research agenda. In I.L. Goldstein (Ed.), Training and development in organization (pp. 376-416). San Francisco: Jossey-Bass.

Field, A. (2009). Discovering statistics using SPSS (3rd ed.). London: SAGE Publications Ltd.

Gist, M. E., Stevens, C. K., \& Bavetta, A. G. (1991). Effects of self-efficacy and post-training intervention on the acquisition and maintenance of complex interpersonal skills. Personnel Psychology, 44, 837861.

Glickman, C. D., \& Tamashiro, R. T. (1982). A comparison of first-year, fifth-year, and former teachers on efficacy, ego development, and problem solving. Psychology in the Schools, 19, 558-562.

Greenberg, J., \& Baron, R. A. (1993). Behavior in organizations: Understanding and managing the human side of work. Needham Heights: Allyn and Bacon.

Gür, G. (2008). A study on the predictors of teachers' sense of efficacy beliefs (Unpublished master's thesis). Middle East Technical University, Institute of Social Science, Graduate School of Social Sciences, Ankara.

Hair, J. F. Jr., Black, W. C., Babin, B. J., \& Anderson, R. E. (2010). Multivariate data analysis (7th ed.). New Jersey: Pearson Prentice Hall.

Haser, Ç., \& Kondakçı, Y. (2011). Genç öğretim elemanlarımın mesleki toplumsallaşması ve akademik kimlik algilarmmn incelenmesi (Project Report). Ankara: TUBITAK.

Haueter, J. A., Macan, T. H., \& Winter, J. (2003). Measurement of newcomer socialization: Construct validation of a multidimensional scale. Journal of Vocational Behavior, 63, 20-39. doi:10.1016/S00018791(02)00017-9

Hrebiniak, L. G., \& Alutto, J. A. (1972). Personal and role-related factors in the development of organizational commitment. Administrative Science Quarterly, 17, 555-573.

Hu, L. T., \& Bentler, T. M. (1999). Cutoff criteria for fit indexes in covariance structure analysis: Conventional criteria versus new alternatives. Structural Equation Modelling: A Multidisciplinary Journal, 6, 1-55. doi:10.1080/10705519909540118

Hulpia, H., \& Devos, G. (2010). Exploring the link between distributed leadership and job satisfaction of school leaders. Educational Studies, 35(2), 153-171. doi:10.1080/03055690802648739

Iqbal, S., Toulson, P., \& Tweed, D. (2011, October). HRM practices and individual knowledge-Sharing. An empirical study of higher education institutions in Pakistan. Proceedings of the 8th International Conference on Intellectal Management and Organizational Learning. Banghok, Thailand.

Jablin, F. M. (1982). Organizational communication: An assimilation approach. In M. E. Roloff, \& C. R. Berger (Eds.), Social cognition and communication (pp. 255-286). Newbury Park, CA: Sage.

Johnsrud, L. K., \& Heck, R. H. (1998). Faculty worklife: Establishing benchmarks across groups. Research in Higher Education, 39(5), 539-555.

Jones, G. R. (1986). Socialization tactics, self-efficacy, and newcomers' adjustments to organizations. Academy of Management Journal, 29, 262-279.

Ketchand, A. A., \& Strawser, J. R. (2001). Multiple dimensions of organizational commitment: Implications for future accounting research. Behavioral Research in Accounting, 13, 221-253.

Kramer, W. K. (2010). Organizational socialization: Joining and leaving organizations. UK: Polity Press.

Leistner, F. (2010). Mastering organizational knowledge flow: How to make knowledge sharing work. Hoboken, New Jersey: John Wiley and Sons Inc.

Locke, E. A. (1976). The nature and causes of job satisfaction. In M. D. Dunnette (Ed.), Handbook of industrial and organizational psychology (pp. 1293-1349). Chicago, IL: Rand McNally.

Louis, M. R. (1980). Surprise and sense making: What newcomers experience in entering unfamiliar organizational settings. Administrative Science Quarterly, 25, 226-234.

Louis, M. R. (1990). Acculturation in the workplace: Newcomers as lay ethnographers. In B. Schneider (Ed.), Organizational climate and culture (pp. 85-129). San Francisco: Jossey-Bass. 
Louis, M. R., Posner, B. Z., \& Powell, G. N. (1983). The availability and helpfulness of socialization practices. Personnel Psychology, 36, 857-866.

Mathieu, J. E., \& Zajac, D. M. (1990). A review and meta-analysis of the antecedents, correlates, and consequences of organizational commitment. Psychological Bulletin, 108(2), 171-194.

Menard, S. (1995). Applied logistic regression analysis. Thousand Oaks, CA: Sage Publications.

Meyer, J. P., Allen, N. J., \& Smith, C. A. (1993). Commitment to organizations and occupations: Extension and test of a three-component conceptualization. Journal of Applied Psychology, 78, 538-551. doi:10.1037/0021-9010.78.4.538

Miller, V. D., \& Jablin, F. M. (1991). Information seeking during organizational entry: Influences, tactics, and a model of the process. Academy of Management Review, 16(1), 92-120.

Moon, M. J. (2000). Organizational commitment revisited in new public management: Motivation, organizational culture, sector, and managerial level. Public Performance and Management Review, 24, 177-194. doi:10.2307/3381267

Nelson, D. L., \& Quick, J. C. (1991). Social support and newcomer adjustment in organizations: Attachment theory at work?. Journal of Organizational Behavior, 12(6), 543-554.

O'Reilly, C. A., \& Chatman, J. (1986). Organizational commitment and psychological attachment: The effects of compliance, identification, and internalization on prosocial behavior. Journal of Applied Psychology, 71, 492-499.

Ok, B. (2007). Correlates of organizational commitment: A special emphasis on organizational communication (Unpublished doctoral dissertation). Middle East Technical University, Graduate School of Social Sciences, Ankara.

Ostroff, C., \& Kozlowski, S. W. J. (1992). Organizational socialization as a learning process: The role of information acquisition. Personnel Psychology, 45, 849-874.

Ostroff, C., \& Kozlowski, S. W. J. (1993). The role of mentoring in the information gathering processes of newcomers during early organizational socialization. Journal of Vocational Behavior, 42, 170-183.

Roehrig, A. D., Bohn, C. M., Turner, J. E., \& Pressley, M. (2008). Mentoring beginning primary teachers for exemplary teaching practices. Teaching and Teacher Education, 24(3), 684-702.

Saks, A. M. (1996). The relationship between the amount and helpfulness of entry training and work outcomes. Human Relations, 49, 429-451.

Saks, A. M., \& Ashforth, B. E. (1997). Organizational socialization: Making sense of the past and present as a prologue for the future. Journal of Vocational Behavior, 51, 234-279. doi:10.1006/jvbe.1997.1614

Saks, A. M., Uggerslev, K. L., \& Fassina, N. E. (2007). Socialization tactics and newcomer adjustment: A meta-analytic review and test of a model. Journal of Vocational Behavior, 70, 413-446. doi:10.1016/j.jvb.2006.12.004

Schein, E. H. (1985). Organizational culture and leadership. San Francisco: Jossey-Bass.

Schein, E. H. (1968). Organizational socialization and the profession of management. Industrial Management Review, 9, 1-15.

Spector, P. E. (1997). Job satisfaction: Application, assessment, causes and consequences. California: Sage Publications Inc.

Steinhaus, C. S., \& Perry, J. L. (1996). Organizational commitment: Does sector matter? Public Productivity \& Management Review, 19(3), 278-288.

Tabachnick, B. G., \& Fidell, L. S. (2007). Using multivariate statistics (5th ed.). Boston, MA: Pearson Education, Inc. Allyn \& Bacon.

Tidwell, M., \& Sias, P. (2005). Personality and information seeking: Understanding how traits influence information-seeking behaviors. Journal of Business Communication, 42(1), 51-77. doi:10.1177/0021943604272028 
Tierney, W. G. (1997). Organizational socialization in higher education. Journal of Higher Education, 68(1), $1-16$.

Thomas, H. D. C., \& Anderson, N. (1998). Changes in newcomers' psychological contracts during organizational socialization: A study of British recruits entering the British Army. Journal of Organizational Behavior, 19, 745-767.

Trowler, P., \& Knight, P. T. (1999). Organizational socialization and induction in universities: Reconceptualizing theory and practice. Higher Education, 37, 177-195.

Tschannen-Moran, M., \& Woolfolk-Hoy, A. (2001). Teacher efficacy: Capturing an elusive construct. Teaching and Teacher Education, 17(7), 783-805. doi:10.1016/S0742-051X(01)00036-1

Ünüvar, T. G. (2006). An integrative model of job characteristics, job satisfaction, organizational commitment, and organizational citizenship behavior (Unpublished doctoral dissertation). Middle East Technical University, Graduate School of Social Sciences, Ankara.

Van Maanen, J., \& Schein, E. H. (1977). Toward a theory of organizational socialization. In B. Staw (Ed.), Annual review of research in organizational behaviour (Vol. 1). Greenwich, CN: JIP Press. Retrieved from http://hdl.handle.net/1721.1/1934

YÖK. (2015). Öğretim elemanı istatistikleri: Öğretim elemanı sayıları. Retrieved from https://istatistik.yok.gov.tr/

Wasti, S. A. (2003). Organizational commitment, turnover intentions and the influence of cultural values. Journal of Occupational and Organizational Psychology, 76, 303-321.

Wharton, R., Potter, P., \& Parry, L. (2004). Keeping the faculty: Issues of socialization, justice, and commitment to the workplace. The Journal of Behavioral and Applied Management, 6(1), 4-20.

Widen-Wulff, G. (2007). The challenges of knowledge sharing in practice: A social approach. Oxford: Chandos Publishing.

Wiener, Y. (1982). Commitment in organizations: A normative view. Academy of Management Review, 7 (3), 418-428.

Wiener, Y. (1988). Forms of value systems: A focus on organizational effectiveness and cultural change and maintenance. Academy of Management Review, 13(4), 534-545.

Wanous, J. P., \& Lawler, E. E. (1972). Measurement and meaning of job satisfaction. Journal of Applied Psychology, 56, 95-105.

Zeffane, R. (1994). Patterns of organizational commitment and perceived management style: A comparison of public and private sector employees. Human Relations, 47, 977-1010. 